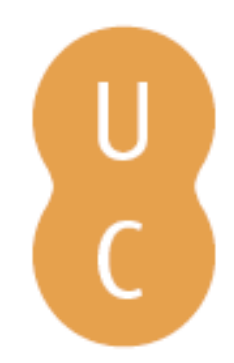

\title{
nombalina
}

\section{Deslocações divinas em territórios humanos: a arte de enfeitiçar de Natália Correia}

Autor(es): $\quad$ Pina, Maria da Graça Gomes de

Publicado por: Imprensa da Universidade de Coimbra; Annablume

URL

persistente:

URI:http://hdl.handle.net/10316.2/40875

DOI:

DOI:https://doi.org/10.14195/978-989-26-1288-1_15

Accessed : $\quad$ 26-Apr-2023 13:05:59

A navegação consulta e descarregamento dos títulos inseridos nas Bibliotecas Digitais UC Digitalis, UC Pombalina e UC Impactum, pressupõem a aceitação plena e sem reservas dos Termos e Condições de Uso destas Bibliotecas Digitais, disponíveis em https://digitalis.uc.pt/pt-pt/termos.

Conforme exposto nos referidos Termos e Condições de Uso, o descarregamento de títulos de acesso restrito requer uma licença válida de autorização devendo o utilizador aceder ao(s) documento(s) a partir de um endereço de IP da instituição detentora da supramencionada licença.

Ao utilizador é apenas permitido o descarregamento para uso pessoal, pelo que o emprego do(s) título(s) descarregado(s) para outro fim, designadamente comercial, carece de autorização do respetivo autor ou editor da obra.

Na medida em que todas as obras da UC Digitalis se encontram protegidas pelo Código do Direito de Autor e Direitos Conexos e demais legislação aplicável, toda a cópia, parcial ou total, deste documento, nos casos em que é legalmente admitida, deverá conter ou fazer-se acompanhar por este aviso. 


\section{Cosmópolis}

\section{mobilidades culturais às origens do pensamento antigo}

Gabriele Cornelli, Maria do Céu Fialho e Delfim Leão

\section{(coords.)}

IMPRENSA DA UNIVERSIDADE DE COIMBRA 


\title{
DESLOCAÇÕES DIVINAS EM TERRITÓRIOS HUMANOS: a arte de enfeitiçar de Natália Correia
}

\author{
(Divine displacements in human territories: Natália Correia's art of charming \\ bewitching)
}

\author{
Maria da Graça Gomes de Pina (mgomesdepina@unior.it) \\ Università degli Studi di Napoli “l'Orientale"
}

Resumo: Uma década antes da sua morte, Natália Correia decide refugiar-se por breve tempo na novelística (sem todavia abandonar a poesia) e publica em 1983 um pequeno volume intitulado $A$ ilha de Circe. A última das novelas, homónima à coletânea, é uma desconstrução, à maneira nataliana, da narração odisseica de Circe, personagem homérica conhecida pelo seu poder enfeitiçador. A reutilização que a Autora faz dessa figura mitológica grega e do locus onde decorre a ação é, segundo as suas palavras, uma mistura de «riso» e de "paixão». Estes dois sentimentos, perno sobre o qual girará toda a ação, representam o modo pelo qual Natália Correia revisita o classicismo e o transplanta para outro terreno, mais próximo da nossa era e decerto um pouco menos mitológico, em que a magia e a arte de enfeitiçar ganham conotações, diria, plenamente humanas, mas onde não deixam de estar presentes também as características fantásticas da maga Circe. Com este contributo, proponho-me portanto analisar o processo narrativo segundo qual os sentimentos de riso e de paixão se entrelaçam com a magia da narração, oferecendo ao leitor uma visão do mundo clássico moderna, proporcionando-lhe e permitindo-lhe um regresso a esse mesmo mundo, sob a guia do cicerone Natália Correia.

Palavras-chave: Natália Correia; A ilha de Circe; riso; paixão

Aвstract: A decade before her death, for a brief period, Natália Correia decides to take shelter in the novel genre (without, however, neglecting poetry) and publishes in 1983 a short volume entitled Circe's Island. The last story, which bears the same title as the volume, is a deconstruction of Homer's narrative of Circe, a character known by her spelling power. The author's re-appropriation of this Greek mythological character and of the locus where the action is played out is, according to her words, a mixture of «laughter» and "passion». These two feelings, around which the entire plot is constructed, represent the way in which Natália Correia revisits classicism and brings it to another land, closer to us and surely less mythological, where magic and the art of spelling acquire fully human features, but where the fantastical features of the witch Circe are also present. It is therefore my aim to analyse the narrative process according to which the feelings of laughter and passion are interweaved with the magic of the narrative, offering to the reader a modern vision of the classical world, allowing the return to that very world under the guidance of Natália Correia. Keywords: Natália Correia; Circe's Island; laughter; passion

ao G., que me peça desobediência, paixão e riso 
«chegou a hora romântica dos deuses nos pedirem a desobediência. Faço-lhes a vontade» (2001: 8), conclui Natália Correia.

Quando se recebe o convite dos deuses a ser-lhes desobediente, qualquer mortal que se preze se precipita a fazer-lhes a vontade. Essa hora, diz-nos Natália Correia, é um momento romântico, um instante irrepetível, em que se tenta a sorte na eterna roleta onde os deuses jogam aos dados com as vidas humanas. É uma ocasião em que, por um brevíssimo segundo, o ser humano tem a impressão e, às vezes também, a ilusão de poder combater contra o que lhe foi predestinado. Outrossim os deuses não escapam ao fado e nada podem contra a Necessidade. A desobediência, pelo contrário, só tem razão de ser e só pode ser levada a cabo quando a necessidade, por um lado, e a vontade, por outro, se unem para possibilitar esse gesto de ruptura e de liberdade que contradistingue a existência humana.

De vontade e de desobediência se fala, também, nos cantos X-XII da Odisseia de Homero, tal como n' $A$ ilha de Circe de Natália Correia, embora se trate de visões diversas e de aplicações diferentes das mesmas faculdades. O ponto em comum é obviamente a deusa Circe e o que os distingue é a utilização que cada um dos autores faz das suas conotações.

\section{ULISSES CHORAVA PALAVRAS TRANSBORDANTES DE COMOÇÃO...}

Após ter narrado, por entre lágrimas mnemónicas de dor lancinante, como conseguira escapar à terrível morte que lhe prometiam os Lestrígones, Ulisses dirige o seu relato e a sua pessoa para a terra de Circe: acha-se só com os companheiros que se conseguiram salvar na única nau que não foi destruída pelos monstros; aproa à ilha Eeia, pátria de Circe «de belas tranças, terrível deusa da fala humana» (Homero 2010: X.136).

Este epíteto, que não é atribuído somente a Circe, mas também a Calipso, por exemplo (cf.XII.449), é uma das poucas, contudo importantes, características - unida à sua voz melodiosa (X.221) - que Ulisses nos oferece da deusa. A outra conotação significativa está ligada aos poderes que tem, a saber, o dom de enfeitiçar todo e qualquer ser vivo, usando o conhecimento que possui das muitas drogas à disposição de quem é sapiente nessa arte. Circe é, assim, uma deusa

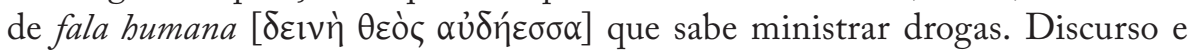
encanto são as suas ferramentas e são esses mesmos filtros que Natália Correia utilizará para pôr em ação o desenrolar de uma história de heróis e de anti-heróis que decidiram fazer a vontade ao pedido de desobediência dos deuses.

\section{NATÁLIA RIA COM PAIXÃO...}

Apesar de muitos serem os autores que regressaram à figura mitológica que, repito, ocupa os cantos X-XII da Odisseia, Circe não é uma das musas que 
os tenha enfeitiçado simplesmente pelas capacidades vinculadas à posse da fala humana e à arte de bem dosar filtros mágicos. A maioria dos escritores que dela tratou viu-a como cínica, sedutora e vingativa, protótipo da femme fatale; portanto, enquadrou-a numa figura feminina tipificada quase unicamente pela sua arte de seduzir, uma tipificação de que a nossa modernidade ainda hoje se alimenta.

Em abono da verdade, também Natália Correia a interpreta como uma deusa sedutora, mas apenas quando a faz baixar na personagem pela qual o nosso herói se apaixona loucamente:

Eficientemente desdobrada em feiticeira dos seus dois apaixonados, a ambos, em olhares e meigura de voz, distribuía equitativamente uma dose de embriaguez, que a qualquer deles convencia de que era o eleito da magnífica mulher (2001: 75).

Contudo, o que me interessa aqui não é tanto essa transposição, quanto a metaforização da fala humana de Circe na narração nataliana. É sobretudo a qualificação de humana de uma fala que é absolutamente divina que pretendo explorar, até porque, de certa forma, o que Natália Correia faz é transmutar esta eterna história de sedução divina em simples (embora complexa) sedução humana, ou seja, entretecer divino e humano, sobrepô-los e invertê-los na sua narrativa. Porém, enquanto que no primeiro caso Ulisses consegue proteger-se do filtro amoroso de Circe com a ajuda de um antídoto, igualmente divino, oferecido por outro deus, Hermes; no segundo, o filtro amoroso insidia-se de modo natural no coração de Adriano, o herói da nossa novela, mas é por mão de outra mortal, miss Hurst, que se torna no fármaco que o prenderá definitiva e 'mortalmente' à sua deusa.

A transmutação dos dois aspetos que ligam a narração homérica à nataliana é feita através do riso e da paixão, sentimentos que representam o modo pelo qual Natália Correia revisita o classicismo e o transplanta para outro terreno, mais próximo da nossa era e decerto um pouco menos mitológico, em que a magia e a arte de enfeitiçar ganham conotações, diria, plenamente humanas, mas onde não deixam de estar presentes também as características fantásticas da maga Circe.

Quando, em abertura do volume, Natália Correia exordia de forma paradoxal a desobedecer aos deuses, o que pretende é precisamente recuperar a figura mitológica e repô-la num circuito narrativo cujo principal escopo é a sua desconstrução. Desconstruir um mito é, de certa forma, torná-lo risível e ao mesmo tempo passível de passionalidade. De maneira que Circe se torna um pretexto, além de um pré-texto, para falar novamente de amor e de paixão, temas eternos da literatura mundial, apesar de na obra em apreço serem apresentados de forma sub-reptícia ao longo da narração. Natália não deseja contar, segundo 
suas palavras, como se verá, uma história fora do comum, que se apresente como pedra-de-toque na literatura portuguesa, ou até mundial. O seu propósito é agitar as mentes e para as agitar o melhor modo é usar aquilo de que dispõe, isto é, «a vida nos seus excessos» (1993: 244) - como afirmou noutra grande obra sua ${ }^{1}$ -, o húmus que aduba as nossas existências. Parte-se, por conseguinte, de um simples caso de conflito de gerações:

E, em realçar-se ser proveitosa a incompatibilidade de Adriano com o pai, tem-se presente que uma grande carreira é sobretudo credora de um pai que o filho não quis tomar como modelo. O que veio realmente a acontecer no domínio das literaturas românicas, onde obteve cátedra e palmas académicas. Mas tais frutos da sua criativa animosidade pelo autor dos seus dias, apresentam-se tardiamente naquela insipidez vital dos homens ilustres que não dá matéria para uma história. E já que destas somos contadores, por amor dos humanos cada vez mais aborrecidos na bicha para o nada de um progresso que lhes capa a imaginação, o Adriano da nossa história é surpreendido na despedida atroz da sua adolescência (2001: 45).

Atente-se na começo da última frase desta citação: «E já que destas somos contadores, por amor dos humanos cada vez mais aborrecidos na bicha para o nada de um progresso que lhes capa a imaginação [...]». Nela vê-se de maneira cristalina o que a impele a narrar esta história, a saber, o amor que tem aos humanos. Não só, percebe-se também a sua intenção de bater-se contra a perda da imaginação humana, que corre o risco de ser minada por um progresso que se mascara de qualidade de vida.

Eis então que ao riso e à paixão supracitados se une a imaginação que $\mathrm{Na}$ tália pretende salvar. A transformação deste mito homérico em facto quotidiano é justificada pelo desejo de salvar uma faculdade que nos caracteriza como seres humanos, ou seja, a imaginação. É sobretudo por meio dela que Natália Correia põe em movimento um enredo aparentemente bizarro em que a deusa Circe aparece e reaparece em cena, sem todavia ser a protagonista, ou melhor, sem que a sua ausência represente propriamente a anulação da sua presença.

Pode parecer também estranho que se esteja agora a falar de imaginação, dado que antes se afirmou que o perno sobre o qual assenta a exegese desta novela é o riso e a paixão. Contudo, um termo não invalida necessariamente os outros dois. Vejamos: regresse-se, por um instante, à expressão «aparentemente bizarro» usada pouco atrás, pois não foi casual. Uma primeira leitura, a que poderíamos chamar de "prazenteira" ou "jocosa", poderia dar azo a que se considerasse que a temática única e central d'A ilha de Circe é deslocar a geografia

\footnotetext{
${ }^{1}$ Refiro-me a Comunicação, obra publicada em 1959, em que Natália descreve o julgamento da Feiticeira Cotovia.
} 
do périplo de Ulisses da Magna Grécia para a costa atlântica, com atenção redobrada sobre a ilha da Madeira (locus onde decorre a ação). Em boa verdade, uma parte consistente dessa interpretação seria correta, porque o que Miss Hurst, personagem de suporte às (des)aventuras de Adriano, faz é realmente desviar a rota do itinerário de Ulisses:

Ulisses vai regressar aos braços da amorável Penélope, que o espera em Ítaca. Mas os ventos funestos desviam-no da rota de Citera e levam-no ao país onde os homens se alimentam de flores. Até aqui nada tenho a opor aos geógrafos da Odisseia. As suas patranhas começam quando, ferido o mar pardacento pelos homéricos remos, Ulisses é impelido para o país dos ciclopes. De coração triste, diz o aedo. Como não havia de confranger-se o Odisseu se são já atlânticas as vagas que hão-de fazer desandar-lhe o navio ao sabor das iras de Poseidon? Porque não é na Sicília que se ergue o gigantesco e sombrio antro da Ciclopeia. É no Atlas. O Atlante (2001: 55-56).

Depreende-se desta exegese 'bizarra' que a Autora constrói para a sua personagem igualmente bizarra («Para definir Miss Emmeline Hurst, numa primeira aproximação, ajusta-se-lhe a aparência de uma catatua empalhada», 2001: 51), que há uma risibilidade de fundo existente e ao mesmo tempo desejada - «[...] se alguém me quiser encontrar, procure-me entre o riso e a paixão», afirmava Natália Correia logo no incipit (2001: 8). E se procurarmos bem por ela, encontramo-la escondida entre as lágrimas de riso que a história de Miss Hurst nos proporciona.

Mas os falsários da geografia da Odisseia não largam a presa. A sua nova vítima é o país dos Lestrijões. A Sardenha. Desta vez o dogma é uma bola de sabão. Os poetas antigos apresentavam os sardos como antropófagos. Eu pergunto: porque privilegiar a Sardenha com essa horripilante gourmandise que se delicia a chupar falangetas humanas, quando os provectos geógrafos dão a costa ocidental de África como o lar dos mais vorazes pantagruéis da antropofagia? Deixemos pois a Sardenha aos abutres da Odisseia (2001: 57).

Todavia, se, por um lado, é verdade que se vê que a Autora brinca de forma irónica com as teorias construídas à volta da geografia do périplo de Ulisses, por outro, é outrossim verdade que essa brincadeira não se esgota em si mesma, não é um fim em si mesma. O que está efetivamente em jogo é salvar os humanos da castração iminente da sua faculdade imaginativa, voltar a dar-lhes a vontade de rir, ou melhor, a capacidade de saberem rir de si mesmos, «[...] naquela ilha embebida nos filtros de Circe» (2001: 45).

Eis então que o riso se transmuta em paixão, e o desvio de rota odisseico de Miss Hurst se entrelaça com a enfatuação do jovem Adriano por uma mulher mais velha, de beleza semelhante à de uma deusa. 
Porque é nesta altura que o coração do jovem sofre a estocada que lhe abre o buraco por onde irá jorrar a droga de Circe (2001: 48).

Esta história paralela, cuja filigrana se vai tornando sempre mais densa, até se transformar em pano duro, reflete o outro verso da medalha, isto é, o da dissolução do mito de Circe, por meio do filtro da paixão, num líquido denso já de substância risível. Porque, a meu ver, o périplo odisseico de Miss Hurst é também uma espécie de apoio jocoso ao desenrolar da história de Adriano, um modo de ornar sapientemente o trágico de comicidade:

[...] os efeitos da magia licantrópica de Circe no sensível Adriano introduziram um argumento ipso facto na sua revolucionária teoria sobre o périplo de Ulisses (2001: 46).

Com este deslocar de conceitos e, ao mesmo tempo, neste deslocar-se posto em ato por Natália Correia, o clássico, e com ele toda a sua carga semântica e imagética, vai ganhando novas formas e contornos que renascem na modernidade. A magia da narração homérica, amalgamada e remodelada na escrita fantasiosa de Natália Correia, volta a encantar e a enfeitiçar as mentes apascentadas e adormecidas da civilização hodierna, metamorfoseando o discurso recebido por mão divina em terrível fala bumana.

[...] seduzida pelo fascinante périplo de Miss Emmeline Hurst, terei eu carregado a paixão de Adriano com influências sobrenaturais quando nela apenas se desgarram as loucuras próprias do primeiro amor? Aceito (2001: 109).

Realizar este propósito, a saber, transmutar o discurso divino em fala humana, requer a intervenção de um deus, ou melhor, de uma 'deusa' de terrível fala bumana, que me parece ser o caso da nossa Autora. Natália Correia detém, a meu ver, esse terrivellextraordinário poder de domar a palavra, tornando-a humana e táctil, ou seja, pondo-a ao alcance dos mortais, e é divina na arte de encantar, procurando impedir que a imaginação humana seja engolida pelo vórtice do vazio mental.

[...] já que o romantismo em que me destemo nesta história clama por um desenlace trágico que sacuda as vossas almas apalermadas pela racionalidade da imbecilidade (2001: 102).

É um conselho, este, que Natália partilha com o leitor, pondo-o na condição de poder descer ao Hades da sua história pessoal e interrogar esse Tirésias, cego e ao mesmo tempo vidente, que poderíamos comparar com a nossa própria consciência. 


\section{III. ...E O LEITOR QUEDAVA ENFEITIÇADO.}

Quem fica enfeitiçado pela narração de Natália Correia deve, forçosamente, possuir uma certa sensibilidade que se deixa atrair, como um íman, para o reino da imaginação, do riso e da paixão. Sentir-se impelido para esse reino obscuro, onde nos perdemos no labirinto das paixões humanas e a realidade se distorce, porque o concreto desaba sob os nossos pés quando o pisamos, é desobedecer ao preceito divino de que tudo está escrito, desenhado e definido. Desobedecer não significa automaticamente prevalecer sobre a lei, mas sim reconhecer que se ousou ir além do estático e do estável, admitindo também a possibilidade de fracassar nesse intento.

Esta história reinventada de Circe, que é deusa, mas também é humana, que é antiga, mas também é moderna, que é imaginária, mas também é real, ensina-nos que não é preciso sermos heróis para entrar nas graças dos deuses, mas é mister mostrar coragem e atrever-se a desobedecer-lhes.

Admito ter falhado em trasladar para estes escritos êxtases e intemperanças do sentimento que nos dão as últimas notícias do homem. Não enjeito o fracasso. Ele é puramente romântico (2001: 8).

Nesse ato de desobediência, a história que se narra e se reescreve torna-se dádiva romântica, onde por romantismo se entende um movimento que mexe com as nossas paixões e sentimentos, em suma, que repõe em ação o contraste entre razão e sentimento, na busca perene da sua síntese. Sempre que isso seja possível, porém o que a Autora nos pede é que insistamos, mesmo que tal síntese possa nunca vir a realizar-se.

«Desculpemo-nos com os deuses» (2001: 109), então, roga Natália, pois se com um ato de desobediência não conseguimos fazer com que eles revivam na nossa existência, com que as suas qualidades e defeitos se tornem nossos, então é porque não nos atrevemos a atravessar as colunas de Héracles da fantasia e da imaginação, não nos deixámos encantar pelo canto das sereias, em suma, não nos rendemos ao riso e à paixão. 


\section{Bibliografia}

\section{Ativa}

Correia, N. (2001), A ilba de Circe. Lisboa.

Homero (2010), Odisseia. Tradução e introdução de Frederico Lourenço. Lisboa.

\section{Passiva}

AA.VV. (2003), Natália Correia, 10 anos depois... Porto.

Abreu, M.F. de et al. (2010), Natália Correia: a festa da escrita. Lisboa.

Correia, M. (1997), "O Romance da Feiticeira Cotovia e o Romanceiro Português”. Millenium 8: 1-8.

Correia, N. (1993), "Comunicação" [1959], in O Sol nas Noites e o Luar nos Dias. Vol. I. Lisboa, 227-51.

Almeida, Â. (2005), O Panteísmo Pentecostal de Natália Correia e o culto do Espirito Santo nos Açores: análise de um inédito. [tese complementar de doutoramento], Lisboa: Universidade Autónoma de Lisboa, 16 de dezembro de 2005.

Almeida, Â. e Costa, F. R. (coord.) (2005), In memoriam Natália Correia. S. Miguel.

Dacosta, F. (2013), O Botequim da Liberdade. Como Natália Correia marcou, a partir de um pequeno bar de Lisboa, o século XX português. Alfragide.

Gomes de Pina, M. da G. (2009a), "Uma transposição atlântica do mito de Circe (Natália Correia)", in M. L. Cusati (a cura di), Portogallo e Mediterraneo, Atti del Convegno Internazionale di Napoli-04-06/10/2007. Napoli, 26576.

Gomes de Pina, M. da G. (2009b), "A 'insularidade textual n'A ilha de Circe de Natália Correia", in AA.VV., Açores 2009: a insularidade, o isolamento e a preservação da lingua portuguesa no mundo. Atas do $4^{\circ}$ Encontro Açoriano da Lusofonia. São Miguel, 106-10.

Gomes de Pina, M. da G., "Mapa biográfico lúdico e distorcido por Natália Correia" [no prelo].

Gomes de Pina, M. da G., "Lusitânia, corpo e voz de uma imagem" [no prelo]. 